\title{
HOTAIR: a key regulator in gynecologic cancers
}

\author{
Jing $\mathrm{Li}^{1}$, Jing Wang ${ }^{2}$, Yan Zhong ${ }^{3}$, Ruixia Guo ${ }^{4}$, Danxia Chu ${ }^{4}$, Haifeng Qiu ${ }^{4^{*}}$ and Zhongfu Yuan ${ }^{4^{*}}$
}

\begin{abstract}
Long non-coding RNAs (IncRNAs) play critical roles in the initiation and progression of human cancers. HOX transcript antisense RNA (HOTAIR) is an IncRNA localized to the mammalian HOXC gene cluster; it can interact with polycomb repressive complex 2 and the lysine-specific histone demethylase/CoREST/REST complex, and it manipulates the expression of various genes. HOTAIR promotes tumor invasion and metastasis by silencing tumor suppressors, and activating oncogenes and signaling pathways. HOTAIR is deregulated in many human cancers; despite its critical roles in health and disease, the underlying mechanisms governing HOTAIR function are unknown. In this review, we summarize the recent findings on the roles of HOTAIR in gynecologic cancers.
\end{abstract}

Keywords: IncRNAs, HOTAIR, Invasion, Metastasis, Cell cycle, Chemoresistance, Radioresistance

\section{Background}

Recently, human transcriptome analyses based on deep sequencing and DNA tiling arrays have revealed that only a small fraction of the genome codes for protein, while up to $70 \%$ is transcribed [1, 2]. Non-coding transcripts, or non-coding RNAs (ncRNAs), are classified into 2 groups based on their length: small ncRNAs that contain less than 200 nucleotides and long ncRNAs (lncRNAs) that contain more than 200 nucleotides. The latter were originally described in high-throughput sequencing analyses of the full-length mouse genome, and characterized by their lack of open reading frames longer than 100 amino acids [3-6]. Similar to messenger RNAs, IncRNAs are transcribed by RNA polymerase II, then capped at the $5^{\prime}$ end, spliced, and polyadenylated at the $3^{\prime}$ end [7]. The human genome is estimated to contain over 10,000 lncRNAs, which often overlap or are interspersed with coding or non-coding transcripts [2, 8, 9]. Most lncRNAs are evolutionarily conserved and strictly regulated, indicating that they are of functional importance $[7,10]$. Many studies have demonstrated that lncRNAs influence the

\footnotetext{
*Correspondence: haifengqiu120@163.com; yfyyzf@163.com

${ }^{4}$ Department of Obstetrics and Gynecology, The First Affiliated Hospital of Zhengzhou University, No. 1, East Jianshe Road, Erqi District, Zhengzhou 450052, Henan, China

Full list of author information is available at the end of the article
}

expression of key genes via several mechanisms, including chromatin modification, and transcriptional and post-transcriptional regulation [11].

HOX transcript antisense RNA (HOTAIR) is a wellstudied IncRNA, which was first identified by Howard Chang in 2007. This 2.2-kb lncRNA is transcribed from the mammalian $H O X C$ gene cluster on chromosome $12 q 13.13$ [12]. As previously reported, HOTAIR interacts with the polycomb repressive complex 2 (the PRC2 complex), which consists of the histone H3 lysine 27 (H3K27) methylase EZH2, SUZ12, and EED, at its $5^{\prime}$ end; binds the lysine-specific histone demethylase (LSD1)/CoREST/REST complex via the $3^{\prime}$ domain; and coordinates the targeting of PRC2 and LSD1to chromatin for coupled histone H3K27 methylation and H3 lysine 4 demethylation [13] (Fig. 1).

Given its important roles, it is unsurprising that the deregulation of HOTAIR has been implicated in various types of human cancer [14-20]. In breast cancer, enhanced HOTAIR expression, which has been detected in both primary tumors and distant metastases, correlates with poor outcomes. HOTAIR also increases cancer invasiveness and metastasis by inducing PRC2 retargeting and affecting the methylation of $\mathrm{H} 3 \mathrm{~K} 27$ [14]. Moreover, HOTAIR is notably elevated in gastric cancer, where it is associated with tumor invasion, 


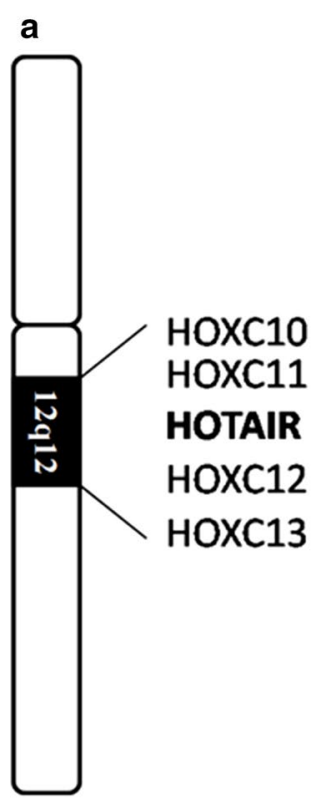

b

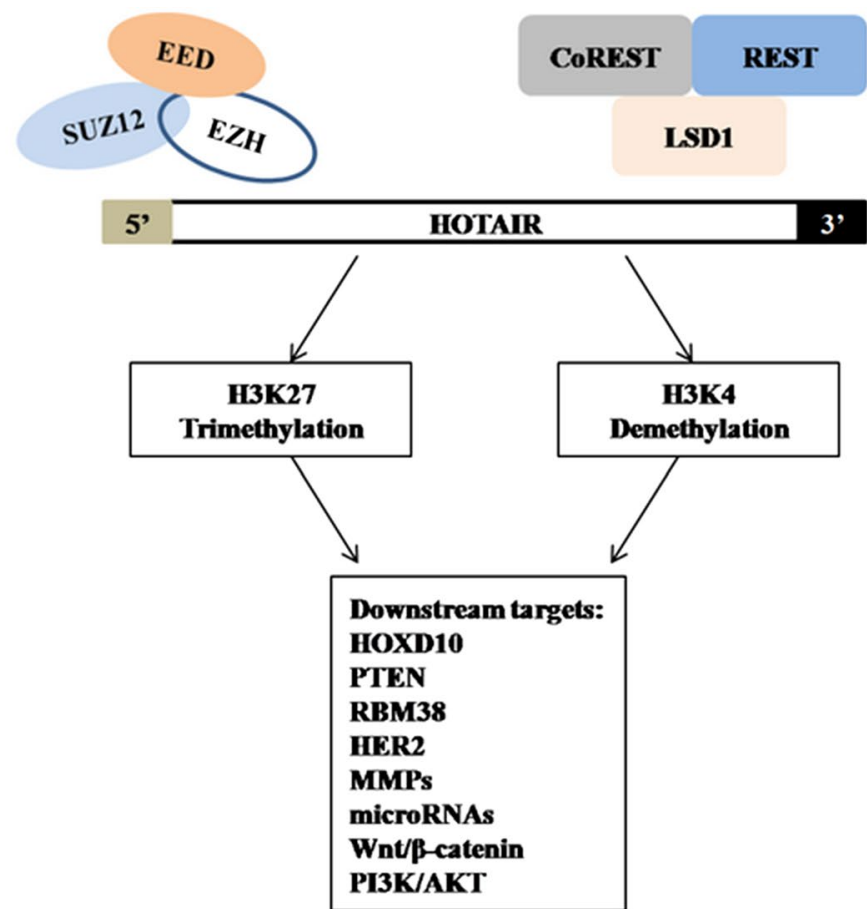

Fig. 1 a the location of HOTAIR in human chromosome 12; $\mathbf{b}$ the schematic illustration of HOTAIR functions. SUZ12, EED and EZH2 are the three components of PRC complex; COREST, REST and LSD1 are the three components of LSD1/CoREST/REST complex

metastases, and poor outcomes [16]. While HOTAIR promotes cellular invasion and the migration of gastric cancer cells, the downregulation of HOTAIR can reverse the epithelial-mesenchymal transition process [21, 22]. In addition, HOTAIR can silence key tumor suppressors, like HOXD10, PTEN, and RBM38, and activate key oncogenes and critical signaling pathways, like HER2, Wnt/ $\beta$-catenin, and PI3K/AKT [19, 23-29]. Intriguingly, abundant HOTAIR induced chemoresistance in lung adenocarcinoma; it promoted cell proliferation and cell cycle progression by inhibiting $\mathrm{p} 21$ [30].

Recently, we have also found that HOTAIR plays a functional role in ovarian, endometrial, and cervical cancers. Herein, we review the functional roles and clinical implications of HOTAIR in gynecologic cancers.

\section{Ovarian cancer}

Ovarian cancer is the most fatal gynecologic malignancy worldwide. It is commonly characterized by the development of pelvic and/or abdominal metastases before symptoms present [31]. As previously reported, alterations in TP53 (the gene for $\mathrm{p} 53$ ) and BRCA1/2 are the most common genomic events in ovarian cancer; they are associated with increased cancer risk and poor prognosis [32, 33]. Interestingly, single nucleotide polymorphisms in HOTAIR were recently found to correlate with susceptibility to ovarian cancer. By genotyping a panel of
1000 Chinese epithelial ovarian cancer patients, Wu et al. demonstrated that rs4759314 and rs7958904 of HOTAIR predict the increased susceptibility to epithelial ovarian cancer. For rs4759314, A allele carriers have a higher cancer risk than G allele carriers (OR 1.34) [34]. Consistent with those findings, we determined that rs920778 ( $\mathrm{T}>\mathrm{C}$ ) of HOTAIR is associated with a statistically significant increase in ovarian cancer risk in 2 separate case-control studies including 329 ovarian cancer patients and 680 cancer-free, age-matched Chinese women. Moreover, our results showed that patients with rs920778 ( $\mathrm{T}>\mathrm{C}$ ) obtained a much shorter survival [35]. The above findings evidenced that SNPs of HOTAIR might be a potent predictive and prognostic marker for ovarian cancer, which warranted further investigations in large populations and different races.

The deregulation of HOTAIR in ovarian cancer has been reported in many studies. By examining the expression of HOTAIR in 44 ovarian cancer and 14 normal ovary tissues, Cui et al. found that HOTAIR is frequently elevated in ovarian cancer, especially in poorly differentiated cases [36]. Similarly, Qiu et al. detected significant upregulation of HOTAIR in ovarian cancer tissues, and this upregulation positively correlated with an advanced International Federation of Gynecology and Obstetrics (FIGO) stage, poor differentiation, and lymph node metastases. Moreover, elevated HOTAIR was also 
an independent prognostic factor for overall survival (OS) and disease-free survival (DFS). The authors also revealed that HOTAIR enhanced cellular proliferation, migration, and invasion by upregulating the expression of cyclin E, Bcl-2, caspase-3 and -9, and matrix metalloproteinase (MMP) 9 and MMP3 [26, 37]. In addition, some $\mathrm{CD} 117^{+} \mathrm{CD} 44^{+}$ovarian cancer stem cells overexpress HOTAIR, and silencing HOTAIR with siRNA impaired the migration and invasion of ovarian cancer stem cells [38]. Interestingly, HOTAIR could also serve as a competing endogenous RNA to sponge its target microRNAs, thus regulating various cellular behaviors $[25,39]$. In ovarian cancer, HOTAIR upregulates the expression of $R A B 22 A$ by sponging microRNA-373, thereby enhancing tumor proliferation and invasion, and decreasing apoptosis [40]. Considering its multiple roles, specific targeting and inhibiting HOTAIR could be a potent strategy for ovarian cancer treatment in the future.

Although more than $80 \%$ of ovarian cancer patients are sensitive to initial platinum-based chemotherapy, most exhibit recurrence and eventually become chemoresistant. Therefore, elucidating the underlying mechanism of chemoresistance is a key issue for ovarian cancer treatment. In carboplatin-treated ovarian cancer patients, Teschendorff et al. found that high levels of HOTAIR are associated with poor prognosis [41]. In addition, HOTAIR induced resistance to cisplatin in vitro by activating NF-kB, PIK3R3, and MAPK1 [42-45]. These observations strongly suggest that HOTAIR plays an important role in inducing chemoresistance in ovarian cancer. In a recent study, we screened the Cancer Genome Atlas (http://cancergenome.nih.gov/) and found that patients with lower HOTAIR expression were more sensitive than their counterparts to platinum-based chemotherapy. Furthermore, using in vitro and in vivo assays, we demonstrated that HOTAIR promotes proliferation and cell cycle progression, and induces resistance to cisplatin via the activation of Wnt/ $\beta$-catenin signal; its effects can be neutralized by treatment with XAV-939, an efficacious Wnt/ $\beta$-catenin inhibitor [46].

Collectively, the pro-cancerous functions of HOTAIR have been well demonstrated, and several SNPs can lead to the abnormal upregulation of HOTAIR. In addition, targeting HOTAIR can overcome the chemoresistance of ovarian cancer, which should be the main topic for us in the future.

\section{Endometrial cancer}

Endometrial cancer mainly comprises endometrioid endometrial cancer (80\%), uterine serous papillary cancer, and clear cell cancer, although it also includes rare cancers [47]. During the last few decades, the incidence of endometrial cancer has continually increased, making it one of the most common cancers in women worldwide. Recent studies suggest that overexpression of HOTAIR contributes to the initiation and progression of endometrial cancer $[48,49]$. Zheng et al. detected overexpression of HOTAIR in endometrial cancer tissues compared to healthy, age-matched controls; overexpression was notably associated with the histological grade of the tumor, the presence of lymph node metastases, the depth of myometrial invasion, and invasion of the lymphovascular space. Moreover, higher HOTAIR expression predicted poorer OS in those patients [48]. In a subsequent study, it was found that high level of HOTAIR correlated with tumor stage, myometrial invasion, and lymph node metastases. Moreover, silencing HOTAIR in vitro resulted in extensive G1 phase arrest and sharp declines in cell proliferation, migration, and invasion [49]. Studies of HOTAIR in other malignancies have mainly focused on its effects on tumor invasion/migration and the eventual development of metastases; however, HOTAIR can strongly enhance cell proliferation by accelerating cell cycle progression. This phenomenon is consistent with the fact that endometrial cancer is mainly localized within the uterine cavity and myometrial invasion occurs in the early stages of disease.

To date, unopposed exposure to estrogen stimulation is the only known etiological factor for endometrial cancer. Interestingly, estradiol is able to induce the expression of HOTAIR via direct binding with estrogen response elements, while the estradiol inhibitor genistein downregulates the level of HOTAIR in prostate cancer cells [50, 51].

Taken together, the overexpression of HOTAIR is a common phenomenon in human endometrial cancer. In vitro assays confirmed its pro-cancerous functions and proposed HOTAIR as an effective target for treating endometrial cancer, especially for the anti-estrogen therapy.

\section{Cervical cancer}

Globally, cervical cancer is still the leading malignancy of the female reproductive tract. More than 529,000 patients worldwide, of which more than $80 \%$ are in developing countries, are annually diagnosed with cervical cancer $[31,52]$. However, the mechanisms underlying the initiation and progression of cervical cancer are still largely unknown. A recent study elucidated a role for HOTAIR in the development of cervical cancer by analyzing 218 pairs of cervical cancer and adjacent normal tissues [53]. The study revealed that HOTAIR is elevated in cervical cancer tissues, where it correlated with more aggressive biological behaviors, such as late tumor stages, lymph node metastases, and deep cervical invasions. Importantly, high levels of HOTAIR were a powerful predictor of poor OS and DFS in these cervical cancer patients 
[53]. Although they highlight the importance of HOTAIR during initiation and progression of cervical cancer, more researches including more patients from different regions are needed in future.

Like that in ovarian cancer, HOTAIR polymorphisms have also been found in cervical cancer. In a southern Chinese cervical cancer group, Guo et al. demonstrated that rs920778 is associated with a high cancer risk; the nucleotide change from $\mathrm{C}$ to $\mathrm{T}$ leads to increased transcriptional activity [54]. Furthermore, we recently demonstrated, in a study of 215 cervical cancer and 430 cancer-free cases, that rs920778 is strongly correlated with the upregulation of HOTAIR [55]. Interestingly, we also found that rs920778 could efficiently predict chemo- and radioresistance in cervical cancer patients. Considering the important roles of rs920778, we are now recruiting ovarian and cervical cancer patients for a large cohort study to verify its value as a cancer-risk predictor.

Although cervical cancer usually responds well to surgery and/or radiotherapy, many patients exhibit radioresistance pre- or post-radiotherapy (innate or acquired resistance) and ultimately die of widespread metastasis [56, 57]. In a recent study, we demonstrated that circulating HOTAIR is markedly upregulated in the sera of cervical cancer patients, and this upregulation is associated with advanced tumor stage, invasion of the lymphovascular space, and lymph node invasion. Furthermore, a follow-up study demonstrated that high levels of HOTAIR positively correlate with tumor relapse and short OS [58]. In another study, we further explored the role of HOTAIR in the regulation of the radiosensitivity of cervical cancer. Using immortalized cervical cancer cells and an animal model, we demonstrated that HOTAIR reduces radiation-induced apoptosis and leads to cellular radioresistance via targeting p21; in contrast, the knockdown of HOTAIR promoted cellular apoptosis and re-sensitized cancer cells to radiotherapy. In addition, we also found that high HOTAIR expression predicts cellular radioresistance [59].

Collectively, a large amount of cervical cancer patients presented abnormal HOTAIR expression, which predicted high cancer risk, resistance to routine therapies and poor prognosis. Although several factors like SNPs and p21 were involved in, more details were still unrevealed yet.

\section{Conclusion}

In summary, the upregulation of HOTAIR frequently occurs in gynecologic malignancies and usually predicts tumor metastases and poor prognosis. In our opinion, three issues should be given priority to be investigated: (1) how to used SNPs of HOTAIR for cancer-risk prediction? (2) how to design specific inhibitors of HOTAIR for clinical use? (3) to further elucidate how HOTAIR participate into chemo- and radio-resistance is urgently required.

\section{Abbreviations}

ncRNA: non-coding RNA; IncRNA: long non-coding RNA; HOTAIR: HOX transcript antisense RNA; PRC2: polycomb repressive complex 2; H3K27: histone H3 lysine 27; OS: overall survival; DFS: disease-free survival; MMP: matrix metalloproteinase.

\section{Authors' contributions}

$\mathrm{HQ}$ and $Z Y$ conceived the idea. JL, JW, YZ, RG and DC did the literature search. All the authors drafted the manuscript. All authors read and approved the final manuscript.

\section{Author details \\ ${ }^{1}$ Department of Oncology, The First Affiliated Hospital of Zhengzhou Univer- sity, Zhengzhou 450052, China. ${ }^{2}$ Department of Obstetrics and Gynecology, Yantai Yuhuangding Hospital Affiliated to the Medical College of Qingdao Uni- versity, Yantai 264000, China. ${ }^{3}$ Department of Gynecological Oncology, Linyi Tumor Hospital, Linyi 276001, China. ${ }^{4}$ Department of Obstetrics and Gynecol- ogy, The First Affiliated Hospital of Zhengzhou University, No. 1, East Jianshe Road, Erqi District, Zhengzhou 450052, Henan, China.}

\section{Acknowledgements}

Not applicable.

\section{Competing interests}

The authors declare that they have no competing interests.

\section{Availability of data and materials}

Data sharing is not applicable as no datasets were generated or analyzed during the current study.

\section{Funding}

This study was supported by the National Natural Science Fundation (81502261 and 81502262), Henan Provincial Health and Family Planning Commission (201503009 and 201503045), and the Program for Science and Technology Innovation Teams in Universities of Henan Province (17IRTSTHN021).

\section{Publisher's Note}

Springer Nature remains neutral with regard to jurisdictional claims in published maps and institutional affiliations.

Received: 3 January 2017 Accepted: 27 May 2017

Published online: 21 June 2017

References

1. Bertone P, Stolc V, Royce TE, Rozowsky JS, Urban AE, Zhu X, Rinn JL, Tongprasit W, Samanta M, Weissman S, et al. Global identification of human transcribed sequences with genome tiling arrays. Science. 2004:306(5705):2242-6.

2. Carninci P, Kasukawa T, Katayama S, Gough J, Frith MC, Maeda N, Oyama $R$, Ravasi T, Lenhard B, Wells C, et al. The transcriptional landscape of the mammalian genome. Science. 2005:309(5740):1559-63.

3. Chen LL, Carmichael GG. Long noncoding RNAs in mammalian cells: what, where, and why? Wiley Interdiscipl Rev RNA. 2010;1 (1):2-21.

4. Lipovich $L$, Johnson $R$, Lin CY. MacroRNA underdogs in a microRNA world: evolutionary, regulatory, and biomedical significance of mammalian long non-protein-coding RNA. Biochim Biophys Acta. 2010;1799(9):597-615.

5. Kapranov P, Cheng J, Dike S, Nix DA, Duttagupta R, Willingham AT, Stadler PF, Hertel J, Hackermuller J, Hofacker IL, et al. RNA maps reveal new RNA classes and a possible function for pervasive transcription. Science. 2007;316(5830):1484-8 
6. Okazaki Y, Furuno M, Kasukawa T, Adachi J, Bono H, Kondo S, Nikaido I, Osato N, Saito R, Suzuki H, et al. Analysis of the mouse transcriptome based on functional annotation of 60,770 full-length cDNAs. Nature. 2002;420(6915):563-73.

7. Guttman M, Amit I, Garber M, French C, Lin MF, Feldser D, Huarte M, Zuk O, Carey BW, Cassady JP, et al. Chromatin signature reveals over a thousand highly conserved large non-coding RNAs in mammals. Nature. 2009;458(7235):223-7.

8. Kapranov P, Drenkow J, Cheng J, Long J, Helt G, Dike S, Gingeras TR. Examples of the complex architecture of the human transcriptome revealed by RACE and high-density tiling arrays. Genome Res. 2005:15(7):987-97.

9. Derrien T, Johnson R, Bussotti G, Tanzer A, Djebali S, Tilgner H, Guernec G, Martin D, Merkel A, Knowles DG, et al. The GENCODE v7 catalog of human long noncoding RNAs: analysis of their gene structure, evolution, and expression. Genome Res. 2012;22(9):1775-89.

10. Hutchinson JN, Ensminger AW, Clemson CM, Lynch CR, Lawrence JB, Chess A. A screen for nuclear transcripts identifies two linked noncoding RNAs associated with SC35 splicing domains. BMC Genom. 2007:8:39.

11. Mercer TR, Dinger ME, Mattick JS. Long non-coding RNAs: insights into functions. Nat Rev Genet. 2009;10(3):155-9.

12. Rinn JL, Kertesz M, Wang JK, Squazzo SL, Xu X, Brugmann SA, Goodnough $\llcorner H$, Helms JA, Farnham PJ, Segal E, et al. Functional demarcation of active and silent chromatin domains in human HOX loci by noncoding RNAs. Cell. 2007;129(7):1311-23.

13. Tsai MC, Manor O, Wan Y, Mosammaparast N, Wang JK, Lan F, Shi Y, Segal E, Chang HY. Long noncoding RNA as modular scaffold of histone modification complexes. Science. 2010;329(5992):689-93.

14. Gupta RA, Shah N, Wang KC, Kim J, Horlings HM, Wong DJ, Tsai MC, Hung $\mathrm{T}$, Argani P, Rinn JL, et al. Long non-coding RNA HOTAIR reprograms chromatin state to promote cancer metastasis. Nature. 2010;464(7291):1071-6.

15. Liu XH, Liu ZL, Sun M, Liu J, Wang ZX, De W. The long non-coding RNA HOTAIR indicates a poor prognosis and promotes metastasis in non-small cell lung cancer. BMC Cancer. 2013;13:464

16. Endo H, Shiroki T, Nakagawa T, Yokoyama M, Tamai K, Yamanami H, Fujiya T, Sato I, Yamaguchi K, Tanaka N, et al. Enhanced expression of long noncoding RNA HOTAIR is associated with the development of gastric cancer. PLOS ONE. 2013:8(10):e77070.

17. Chen FJ, Sun M, Li SQ, Wu QQ, Ji L, Liu ZL, Zhou GZ, Cao G, Jin L, Xie $H W$, et al. Upregulation of the long non-coding RNA HOTAIR promotes esophageal squamous cell carcinoma metastasis and poor prognosis. Mol Carcinog. 2013;52(11):908-15.

18. Ono H, Motoi N, Nagano H, Miyauchi E, Ushijima M, Matsuura M, Okumura S, Nishio M, Hirose T, Inase N, et al. Long noncoding RNA HOTAIR is relevant to cellular proliferation, invasiveness, and clinical relapse in small-cell lung cancer. Cancer Med. 2014;3(3):632-42.

19. Li D, Feng J, Wu T, Wang Y, Sun Y, Ren J, Liu M. Long intergenic noncoding RNA HOTAIR is overexpressed and regulates PTEN methylation in laryngeal squamous cell carcinoma. Am J Pathol. 2013;182(1):64-70.

20. Chisholm KM, Wan Y, Li R, Montgomery KD, Chang HY, West RB. Detection of long non-coding RNA in archival tissue: correlation with polycomb protein expression in primary and metastatic breast carcinoma. PLoS ONE. 2012;7(10):e47998.

21. Xu ZY, Yu QM, Du YA, Yang LT, Dong RZ, Huang L, Yu PF, Cheng XD. Knockdown of long non-coding RNA HOTAIR suppresses tumor invasion and reverses epithelial-mesenchymal transition in gastric cancer. Int J Biol Sci. 2013;9(6):587-97.

22. Lee NK, Lee JH, Park CH, Yu D, Lee YC, Cheong JH, Noh SH, Lee SK. Long non-coding RNA HOTAIR promotes carcinogenesis and invasion of gastric adenocarcinoma. Biochem Biophys Res Commun. 2014;451(2):171-8.

23. Nakayama I, Shibazaki M, Yashima-Abo A, Miura F, Sugiyama T, Masuda T, Maesawa C. Loss of HOXD10 expression induced by upregulation of miR$10 \mathrm{~b}$ accelerates the migration and invasion activities of ovarian cancer cells. Int J Oncol. 2013;43(1):63-71.

24. Ding C, Cheng S, Yang Z, Lv Z, Xiao H, Du C, Peng C, Xie H, Zhou L, Wu J, et al. Long non-coding RNA HOTAIR promotes cell migration and invasion via down-regulation of RNA binding motif protein 38 in hepatocellular carcinoma cells. Int J Mol Sci. 2014;15(3):4060-76.

25. Liu XH, Sun M, Nie FQ, Ge YB, Zhang EB, Yin DD, Kong R, Xia R, Lu KH, Li $J H$, et al. Lnc RNA HOTAIR functions as a competing endogenous RNA to regulate HER2 expression by sponging miR-331-3p in gastric cancer. Mol Cancer. 2014;13:92.
26. Qiu J, Lin YY, Ye LC, Ding JX, Feng WW, Jin HY, Zhang Y, Li Q, Hua KQ. Overexpression of long non-coding RNA HOTAIR predicts poor patient prognosis and promotes tumor metastasis in epithelial ovarian cancer. Gynecol Oncol. 2014;134(1):121-8.

27. Carrion K, Dyo J, Patel V, Sasik R, Mohamed SA, Hardiman G, Nigam V. The long non-coding HOTAIR is modulated by cyclic stretch and WNT/betaCATENIN in human aortic valve cells and is a novel repressor of calcification genes. PLOS ONE. 2014;9(5):e96577.

28. Yang G, Zhang S, Gao F, Liu Z, Lu M, Peng S, Zhang T, Zhang F. Osteopontin enhances the expression of HOTAIR in cancer cells via IRF1. Biochim Biophys Acta. 2014;1839(9):837-48.

29. Zhang H, Cai K, Wang J, Wang X, Cheng K, Shi F, Jiang L, Zhang Y, Dou J. MiR-7, inhibited indirectly by LincRNA HOTAIR, directly inhibits SETDB1 and reverses the EMT of breast cancer stem cells by downregulating the STAT3 pathway. Stem Cells. 2014;32:2858-68.

30. Liu Z, Sun M, Lu K, Liu J, Zhang M, Wu W, De W, Wang Z, Wang R. The long noncoding RNA HOTAIR contributes to cisplatin resistance of human lung adenocarcinoma cells via downregualtion of p21(WAF1/CIP1) expression. PLoS ONE. 2013;8(10):e77293.

31. Siegel R, Ma J, Zou Z, Jemal A. Cancer statistics, 2014. CA Cancer J Clin. 2014;64(1):9-29.

32. Vaughan S, Coward JI, Bast RC Jr, Berchuck A, Berek JS, Brenton JD, Coukos G, Crum CC, Drapkin R, Etemadmoghadam D, et al. Rethinking ovarian cancer: recommendations for improving outcomes. Nat Rev Cancer. 2011;11(10):719-25

33. Bowtell DD, Bohm S, Ahmed AA, Aspuria PJ, Bast RC Jr, Beral V, Berek JS, Birrer MJ, Blagden S, Bookman MA, et al. Rethinking ovarian cancer II: reducing mortality from high-grade serous ovarian cancer. Nat Rev Cancer. 2015;15(11):668-79.

34. Wu H, Shang X, Shi Y, Yang Z, Zhao J, Yang M, Li Y, Xu S. Genetic variants of IncRNA HOTAIR and risk of epithelial ovarian cancer among Chinese women. Oncotarget. 2016;7(27):41047-52.

35. Qiu H, Wang X, Guo R, Liu Q, Wang Y, Yuan Z, Li J, Shi H. HOTAIR rs920778 polymorphism is associated with ovarian cancer susceptibility and poor prognosis in a Chinese population. Future oncology. 2016.

36. Cui L, Xie XY, Wang H, Chen XL, Liu SL, Hu LN. Expression of long non-coding RNA HOTAIR mRNA in ovarian cancer. J Sichuan Univ. 2013;44(1):57-9.

37. Qiu JJ, Wang Y, Ding JX, Jin HY, Yang G, Hua KQ. The long non-coding RNA HOTAIR promotes the proliferation of serous ovarian cancer cells through the regulation of cell cycle arrest and apoptosis. Exp Cell Res. 2015;333(2):238-48.

38. Wang J, Chen D, He X, Zhang Y, Shi F, Wu D, Chen J, Zhang Y, Zhao F, Dou J. Downregulated lincRNA HOTAIR expression in ovarian cancer stem cells decreases its tumorgeniesis and metastasis by inhibiting epithelialmesenchymal transition. Cancer Cell Int. 2015;15:24.

39. Xing CY, Hu XQ, Xie FY, Yu ZJ, Li HY, Bin Z, Wu JB, Tang LY, Gao SM. Long non-coding RNA HOTAIR modulates C-KIT expression through sponging miR-193a in acute myeloid leukemia. FEBS Lett. 2015:589(15):1981-7.

40. Zhang Z, Cheng J, Wu Y, Qiu J, Sun Y, Tong X. LncRNA HOTAIR controls the expression of Rab22a by sponging miR-373 in ovarian cancer. Mol Med Rep. 2016;14(3):2465-72.

41. Teschendorff AE, Lee $S H$, Jones A, Fiegl H, Kalwa M, Wagner W, Chindera K, Evans I, Dubeau L, Orjalo A, et al. HOTAIR and its surrogate DNA methylation signature indicate carboplatin resistance in ovarian cancer. Genome Med. 2015;7:108.

42. Wang $Y$, Wang $H$, Song T, Zou Y, Jiang J, Fang L, Li P. HOTAIR is a potential target for the treatment of cisplatinresistant ovarian cancer. Mol Med Rep. 2015;12(2):2211-6.

43. Yiwei T, Hua H, Hui G, Mao M, Xiang L. HOTAIR interacting with MAPK1 regulates ovarian cancer skov3 cell proliferation, migration, and invasion. Med Sci Monit Int Med J Exp Clin Res. 2015;21:1856-63.

44. Dong L, Hui L. HOTAIR promotes proliferation, migration, and invasion of ovarian cancer SKOV3 cells through regulating PIK3R3. Med Sci Monit Int Med J Exp Clin Res. 2016;22:325-31.

45. Ozes AR, Miller DF, Ozes ON, Fang F, Liu Y, Matei D, Huang T, Nephew KP. NF-kappaB-HOTAIR axis links DNA damage response, chemoresistance and cellular senescence in ovarian cancer. Oncogene. 2016;35(41):5350-61.

46. Li J, Yang S, Su N, Wang Y, Yu J, Qiu H, He X. Overexpression of long noncoding RNA HOTAIR leads to chemoresistance by activating the Wnt/ beta-catenin pathway in human ovarian cancer. Tumour Biol. 2015. 
47. Di Cristofano A, Ellenson LH. Endometrial carcinoma. Annu Rev Pathol. 2007:2:57-85

48. He X, Bao W, Li X, Chen Z, Che Q, Wang H, Wan XP. The long non-coding RNA HOTAIR is upregulated in endometrial carcinoma and correlates with poor prognosis. Int J Mol Med. 2014;33(2):325-32.

49. Huang J, Ke P, Guo L, Wang W, Tan H, Liang Y, Yao S. Lentivirus-mediated RNA interference targeting the long noncoding RNA HOTAIR inhibits proliferation and invasion of endometrial carcinoma cells in vitro and in vivo. Int J Gynecol Cancer. 2014;24(4):635-42.

50. Chiyomaru T, Yamamura S, Fukuhara S, Yoshino H, Kinoshita T, Majid S, Saini S, Chang I, Tanaka Y, Enokida H, et al. Genistein inhibits prostate cancer cell growth by targeting miR-34a and oncogenic HOTAIR. PLoS ONE. 2013;8(8):e70372.

51. Bhan A, Hussain I, Ansari KI, Kasiri S, Bashyal A, Mandal SS. Antisense transcript long noncoding RNA (IncRNA) HOTAIR is transcriptionally induced by estradiol. J Mol Biol. 2013;425(19):3707-22.

52. Jemal A, Bray F, Center MM, Ferlay J, Ward E, Forman D. Global cancer statistics. CA Cancer J Clin. 2011;61 (2):69-90.

53. Huang L, Liao LM, Liu AW, Wu JB, Cheng XL, Lin JX, Zheng M. Overexpression of long noncoding RNA HOTAIR predicts a poor prognosis in patients with cervical cancer. Arch Gynecol Obstet. 2014;290:717-23.
54. Guo L, Lu X, Zheng L, Liu X, Hu M. Association of long non-coding RNA HOTAIR polymorphisms with cervical cancer risk in a Chinese population. PLOS ONE. 2016;11(7):e0160039.

55. Qiu H, Liu Q, Li J, Wang X, Wang Y, Yuan Z, Li J, Pei DS. Analysis of the association of HOTAIR single nucleotide polymorphism (rs920778) and risk of cervical cancer. APMIS. 2016;124(7):567-73.

56. Yee GP, de Souza P, Khachigian LM. Current and potential treatments for cervical cancer. Curr Cancer Drug Targets. 2013;13(2):205-20.

57. Dutta S, Nguyen NP, Vock J, Kerr C, Godinez J, Bose S, Jang S, Chi A, Almeida F, Woods W, et al. Image-guided radiotherapy and -brachytherapy for cervical cancer. Front Oncol. 2015;5:64.

58. Li J, Wang Y, Yu J, Dong R, Qiu H. A high level of circulating HOTAIR is associated with progression and poor prognosis of cervical cancer. Tumour Biol. 2015;36:1661-5.

59. Jing L, Yuan W, Ruofan D, Jinjin Y, Haifeng Q. HOTAIR enhanced aggressive biological behaviors and induced radio-resistance via inhibiting p21 in cervical cancer. Tumour Biology. 2015;36(5):3611-9.

\section{Submit your next manuscript to BioMed Central and we will help you at every step:}

- We accept pre-submission inquiries

- Our selector tool helps you to find the most relevant journal

- We provide round the clock customer support

- Convenient online submission

- Thorough peer review

- Inclusion in PubMed and all major indexing services

- Maximum visibility for your research

Submit your manuscript at www.biomedcentral.com/submit 